\title{
SOBRE BEETHOVEN, O SILÊNCIO DE HEGEL
}

\section{THE HEGEL'S SILENCE ABOUT BEETHOVEN}

\author{
Lucas Eduardo da Silva Calon \\ Universidade de São Paulo \\ lucasgalon@gmail.com
}

\section{Resumo}

É amplamente reconhecida a magnitude que ganhou a música como objeto do pensamento filosófico no século XIX. Mesmo compositores, antes considerados na condição de artesãos, tornaramse pensadores influentes, na esteira da importância da música no pensamento de grandes filósofos. Ludwig van Beethoven (1770-1827) se destaca como pioneiro de uma tendência que culminará na relevância adquirida por Richard Wagner para a história da filosofia: no século XIX os mais importantes filósofos darão certa primazia à estética - incluindo a musical - há pouco organizada como disciplina. É o caso de C. W. F. Hegel (1770-1831), o mais influente filósofo contemporâneo de Beethoven. A hipótese deste estudo parte da não relação entre esses dois importantes protagonistas, o que, na conjuntura histórica indicada, é estranhamente notável. Hegel, em suas muitas preleções dedicadas à arte e à música, jamais cita Beethoven entre os muitos compositores dos quais lança mão como seus exemplos; além disso, é possivel que haja determinadas censuras veladas de caráter poético-estilístico desenvolvidas em seus escritos, aplicáveis à música do compositor alemão. Por outro lado, embora não haja registro de comentários de Beethoven acerca de sua ausência na filosofia de Hegel, a hipótese deste estudo sugere que a resposta ao programa hegeliano possa ter se dado no campo artístico, especificamente através de sua Nona Sinfonia. Nesse sentido, a conjunção arte-filosofia, tomada no âmbito da relação entre compositores e filósofos, pode encontrar aqui uma prévia menos ruidosa do consagrado embate Nietzsche-Wagner. Assim sendo, devido aos muitos pontos movediços que são base da hipótese proposta, curiosamente, este ensaio visa especular justamente sobre aquilo que surge do silêncio de ambos os atores em questão: aquilo que Hegel não disse, e o que este silêncio quer dizer; aquilo que 
Beethoven não expôs em forma de registro escrito, respondendo ao silêncio hegeliano sobre si com uma obra musical, e a efetividade desta resposta.

Palavras-chave: filosofia da arte; Beethoven; Hegel.

\section{Abstract}

The magnitude that music gained as an object of philosophical thought in the 19th century is widely recognized. Even composers, previously considered as artisans, became influential thinkers, in the wake of the importance of music in the thinking of great philosophers. Ludwig van Beethoven (1770-1827) stands out as a pioneer of a trend that would culminate in the relevance acquired by Richard Wagner for the history of philosophy: in the 19th century, the most important philosophers would confer a certain primacy to aesthetics - including musical - recently organized as a subject. This is the case of G. W. F. Hegel (1770-1831), Beethoven's most influential contemporary philosopher. The hypothesis of this study starts from the non-relation between these two important protagonists, which, in that historical context, is strangely remarkable. Hegel, in his many lectures devoted to art and music, never mentions Beethoven among the many composers he uses as examples; moreover, there may be certain veiled censures of a poetic-stylistic character developed in his writings, applicable to the music of the German composer. On the other hand, although there is no record of Beethoven's comments about his absence in Hegel's philosophy, the hypothesis of this study suggests that the answer to the Hegelian program may have taken place in the artistic field, specifically through his Ninth Symphony. In this sense, the conjunction of art and philosophy, taken in the context of the relationship between composers and philosophers, can find here a less noisy preview of the renowned Nietzsche-Uagner clash. Therefore, due to the many shifting points that are the basis of the proposed hypothesis, curiously, this essay aims to speculate precisely on what arises from the silence of both actors in question: what Hegel did not say, and what this silence means; what Beethoven did not expose in the form of a written record, responding to the Hegelian silence about himself with a musical opus, and the effectiveness of this response.

Keywords: philosophy of art; Beethoven; Hegel. 


\section{Introdução}

Contemporâneo de Beethoven, o velho Hegel parece ignorá-lo ou olhar sua obra com aquele olímpico desdém que marca tantas vezes o juízo dos contemporâneos. Os outros cinco grandes da música alemã estão presentes no seu tratado. Dos estranhos, até Rossini - rebento italiano de Mozart - merece o favor de uma citação. Só o nome de Beethoven - com toda influência hegeliana que Werner Korte foi descobrir na Sonata op. 90 - não aparece uma só vez nessas páginas quase amenas em que o filósofo parece tomar férias de todas as suas canseiras especulativas (UACNER, 1987, p. 7).

Theoderico Tostes, poeta e tradutor, na apresentação da primeira edição brasileira do ensaio "Beethoven" de Richard Wagner (1987), é quem primeiro levanta algumas questões que aqui se configuram como hipótese a ser desenvolvida em forma de um estudo em filosofia e música. Este estudo tem como objeto o silêncio de Hegel com relação a Beethoven e como isso se desdobra num sentido que pode contribuir para pensar a relação entre a música e a filosofia. Deve-se dar crédito a Tostes pela retomada de uma percepção de estranheza pela não relação entre os dois mais influentes ícones de uma mesma época e lugar, percepção essa deduzida do pensamento estético de Hegel, cristalizado a posteriori em seus Cursos de Estétical. Deve-se a ele também o levantamento de uma inusitada especulação, sugerida a partir da afirmação de Hegel de que os poemas de Schiller seriam "muito pesados e inaproveitáveis para a composição musical" (p. 288). É quase insuperável então a tentação da pergunta: seria a Nona ${ }^{2}$ uma resposta provocativa do compositor ao silêncio do filósofo? Se fosse, o que isto significaria? Estas perguntas especulativas são mote para

I Todas as referências a Hegel neste estudo são dos Cursos de Estética, 1835 [2002]. 2 Aos leitores menos familiarizados com aspectos mais específicos da história da música, basta relembrar que a nona e última sinfonia de Beethoven é a primeira a utilizar um texto cantado. Novidade por si só revolucionária, utilizar a voz humana num gênero de música puramente instrumental (a sinfonia) é o que menos interessa para o presente estudo. Que se entoe justamente um poema de Friedrich Schiller (1759-1805) é o que realmente interessa. 
que neste estudo se discuta, além do problema Hegel-Beethoven, a própria relação entre o pensamento filosófico e a arte, entre estética e poética, os limites epistemológicos da filosofia estética, bem como as dificuldades inerentes a qualquer abordagem de elementos da moínois pelo pensamento filosófico.

\section{A organização da estética: a música envolta em desconfiança}

- século XVIII viu surgir a estética entendida como campo específico da filosofia. É bem sabido que se trata mais da organização da filosofia no sentido da especificidade do pensamento sobre arte, e a aplicação do nome como conceito abarcador daquilo que seria considerado um ramo da filosofia, do que propriamente o surgimento de uma filosofia estética com tudo aquilo que ela deve ter. Nesse sentido, quase não é preciso dizer, os gregos possuíam já uma consistente filosofia da arte, nunca pensada como ramificação ou campo apartado, e sim como a filosofia inteira ${ }^{3}$. Ainda que incipiente quanto à categorização e divisões epistemológicas da arte, alguns pensadores como Diderot, Shaftesburry, e principalmente Kant, lançam bases relativamente sólidas para essa primeira organização geral.

Para o que interessa na reflexão que se seguirá, é essencial a lembrança de que, no século XVIII, o pensamento sobre as artes plásticovisuais e a poesia se encontravam em primeiro plano, recebendo maior atenção dos filósofos, que inclusive thes atribuíam uma suposta superioridade (a comparação entre as "belas artes" aparece quase como um topos). Nesta comparação, à música, devido ao seu logos próprio de arte do som no tempo, atribui-se uma posição de clara desconfiança e evidentes desvantagens. Immanuel Kant é quem expõe de forma mais clara essa desconfiança, que pode ser deduzida da Crítica da Faculdade do Juízo (1793), lançando mão de disposições hierárquicas na comparação entre as belas artes, deixando entrever os motivos para a valoração atribuída a cada uma. E é particularmente interessante a ambiguidade kantiana com relação à música, o que não é surpreendente, já que para ele as belas artes, se desconectadas de ideias morais, decaem em movimentos de dispersão, especialmente aptas

3 Modo de visão primordial que será recuperada especialmente por Martin Heidegger (1889-1976) e Luigi Pareyson (1918-1991) já no século XX. 
a afugentar o descontentamento do ânimo. Sua posição, na verdade, é oscilante, quando se muda o parâmetro passa-se da vantagem à desvantagem:

Depois da poesia, se o que importa é o movimento do ânimo, eu poria aquela que entre as artes elocutivas mais se the aproxima e assim também permite unificar-se muito naturalmente com ela, a saber, a arte do som (Tonkunst). Pois embora ela fale por meras sensações sem conceitos, por conseguinte não deixa como a poesia sobrar algo para a reflexão, ela contudo move o ânimo de modo mais variado e, embora mais passageiro, no entanto mais íntimo; mas ela é certamente mais gozo que cultura (...) e, ajuizada pela razão, possui valor menor que qualquer outra das belas artes (KANT, 2012, \$53).

Kant reflete um problema antigo, que permeia inconsciente esse movimento inicial de organização da estética (pensada como uma epistemologia diferenciada): a compreensão da música "pura" (leiase instrumental, sem palavras para suportá-la ou ser suportada por ela), cujas ideias estéticas não apresentariam "nenhum conceito e pensamento determinado". Doravante,

Se, contrariamente, se apreciar o valor das belas artes segundo a cultura que elas proporcionam ao ânimo e tomar como padrão de medida o alargamento das faculdades que na faculdade do juízo têm que concorrer para o conhecimento, então a música possui entre as belas artes o último lugar (...), porque ela joga simplesmente com sensações (KANT, 2012, \$53).

Em outras palavras, considera-se que da música instrumental não emana sentidos objetivos, passiveis de delimitação de significados, e por isso, tanto maior sua eminência artística, menor sua eminência cultural $^{4}$. Vê-se então o delineamento de um paradoxo que em parte atualizou um problema antigo, que ainda se mantém pregnante na

4 Pode-se conferir Carl Dahlhaus (2003), que examina especificamente esta dimensão da estética musical de Kant, fazendo-lhe a crítica.

\section{3}

REV. TULHA, RIBEIRÃO PRETO, v. 5, n. 2, pp. 259-287, jul.-dez. 2019 
filosofia da música. Essa oscilação de posições relacionadas à música que se vê nas asseverações de Kant, antecipa as posições que serão tomadas, mesmo em posturas antagônicas, pelos diversos filósofos ao longo do século XIX. Na circunvizinhança desta desconfiança é possível notar algo da influência kantiana na visão que terá Hegel sobre a música, malgrado esta mesma visão possa ter dado início às grandes mudanças de rumo que resultarão em posições predominantes no pensamento musical romântico. Os Cursos de Estética surgem a partir da organização das preleções de Hegel sobre artes ${ }^{5}$, ministradas a partir de 1818, aperfeiçoadas posteriormente e publicadas postumamente em 1835. Neles, Hegel não só esboça muitas questões decisivas para a configuração do pensamento romântico sobre arte como já apresenta várias tendências para uma organização disciplinar mais desenvolvida. Apesar de ser um marco desta virada, ainda no caso da música é possível encontrar certo desconforto com relação à ambiguidade explicita no dilema kantiano6. No entanto, Hegel procura deslocar o problema para outro âmbito, cujo exame é importante para a configuração contextual que agora se apresenta neste estudo. A estética musical de Hegel apresentada nos Cursos evidencia a desenvoltura com que o filósofo alemão lida com um pensamento mais geral sobre a música (que ainda sim é muito específico), tendo a cautela de sempre advertir que pretende se aplicar aos seus aspectos mais universais, devido as suas próprias e sempre admitidas limitações técnicas no campo desta arte em especial. Isto é digno de nota, pois muito importante para a compreensão de

5 Os Cursos mostram a completude quase totalizadora que o filósofo busca na abordagem sobre a arte, e aponta tendências que se consolidarão em Schopenhaver e Nietzsche com relação à música, mesmo que de forma ainda pregnante do pensamento kantiano e tímida com relação aos seus sucessores: uma autêntica virada de percepção, em que a sua impossibilidade semântica - apontada como sua suposta fraqueza por Kant - torna-se aos poucos, na compreensão do espírito romântico, a sua maior vantagem. Assim sendo, essa ausência de objetividade semântica conotará a presença concreta de um âmbito maior de possibilidades de significação que, subjetivas, se relacionam com o campo da interioridade.

6 Pode-se dizer que em Hegel as questões relacionadas ao significado da música serão colocadas no âmbito do debate entre os adeptos da música programática e a posição que parte da recepção considerou como "formalista" (geralmente uma má compreensão), de Eduard Hanslick (1825-1904), embate crucial para se entender a música na segunda metade do século XIX.

\section{4}

REV. TULHA, RIBEIRÃO PRETO, v. 5, n. 2, pp. 259-287, jul.-dez. 2019 
como Hegel lida com o problema kantiano já aqui apresentado?, servindo para que melhor se possa dimensionar questões concernentes à hipótese que aqui se desenvolve. Nas palavras de Hegel:

Se quisermos agora, depois desta indicação geral do princípio e da divisão da música, prosseguir para a discussão de seus lados particulares, surge então, segundo a natureza da coisa, uma dificuldade própria. A saber, pelo fato de que o elemento do som e da interioridade, para o qual se impulsiona o conteúdo, é tão abstrato e formal, não pode ser feita outra transição ao particular a não ser que se recaia imediatamente nas determinações técnicas, nas relações de medida dos sons, nas diferenciações dos instrumentos, nas tonalidades, nos acordes etc. Mas neste âmbito sou pouco versado e, por isso, devo me desculpar de antemão se eu apenas me restringir aos pontos de vista mais universais e às observações isoladas (HECEL, 2002, p. 281).

Outro aspecto importante para o que neste estudo se busca: vêse que Hegel também compara as variadas formas artísticas tipificando muitos de seus aspectos exteriores. É numa dessas abordagens que se pode deduzir uma sua tentativa de mitigar o problema kantiano com relação à música, sem de fato abandoná-lo.

Particularmente em época mais recente a música, rompendo com um conteúdo por si mesmo já claro, retornou assim ao seu próprio elemento, mas para isso perdeu também tanto mais poder sobre todo o interior, na medida em que o prazer que ela pode oferecer apenas se volta para um lado da arte, ao mero interesse, a saber, para o que é puramente musical da composição e sua habilidade, um lado que é apenas questão para especialista e importa

7 A demonstração de certo desconforto devido a um não versamento técnico em arte não é prerrogativa de Hegel. Embora a filosofia não tenha se ocupado em analisar o quanto poderia ser decisivo um conhecimento técnico específico do filosofo na lida com os problemas da arte, é possivel, sem tanto esforço, coletar as muitas escusas, dos mais diferentes filósofos, quanto a esta dificuldade. Não é ocasião de se realizar aqui um levantamento dos diversos casos. Mas seria interessante se um levantamento como este resultasse ou fosse parte de uma espécie de história da relação entre os filósofos e as artes, a partir, quem sabe, de uma "analítica da precariedade" desta relação.

\section{5}

REV. TULHA, RIBEIRÃO PRETO, v. 5, n. 2, pp. 259-287, jul.-dez. 2019 
menos ao interesse artístico universalmente humano (HECEL, 2002, p. 287).

Tomadas estas duas asseverações de Hegel, vê-se que se mantém implícita em sua estética musical a pregnância do problema kantiano. Se em primeiro lugar ele admite ser pouco versado em questões técnicas musicais (o que se poderia tomar como especificidades da moínoıs), é para em seguida condenar o que é "puramente musical" justamente por este representar um lado da arte que deve interessar somente ao especialista. Neste ponto o problema kantiano se transforma no problema hegeliano. A desconfiança de Kant para com a ausência de sentidos da música pura é a desconfiança de Hegel de que haja menos interesse artístico universalmente humano naquilo que se volta para o que é puramente musical. Chega-se aqui à configuração de parte do contexto filosófico que suporta o problema musical mais importante da presente hipótese: a questão das determinações técnicas da música e sua importância para a análise filosófica talvez seja a primeira força motriz para as formulações de Hegel, ao menos daquelas que serão decisivas para o estudo da questão Hegel-Beethoven.

\section{Hegel e a relação música-palavra: filosofia ou prescrição?}

A partir da leitura que se propôs até aqui, pode-se considerar que a colocação de Hegel das questões técnicas da música como sendo de menor interesse para filosofia não é apenas uma forma de escapar aos seus aspectos menos universais. São uma estratégia que, por um lado conveniente (ser versado no que é menos importante não prejudicaria sua abordagem), por outro deixa à vontade o filósofo na análise de aspectos da música que supostamente seriam mais relevantes para a filosofia. Entenda-se então por relevante aquilo que seria compreensivel não somente para o especialista. Justamente aquilo que Kant incluiria no universo da "cultura" e que para Hegel seria de interesse artístico universalmente humano, pois eivado de possibilidades de delimitação de significado: a música em sua fusão com a arte da palavra.

Hegel busca então examinar o problema da relação músicatexto, como se esse não fosse também um problema técnico dos mais 
importantes $^{8}$. À vontade num campo aparentemente mais seguro, apresenta um pensamento fluente o bastante para inclusive prescrever as melhores formas de adaptação do texto à música, comentar e especular sobre o equilibrio entre ambas, demonstrar aquilo que melhor representaria seus exemplos no campo dos diversos estilos composicionais, citando diversos compositores - de várias épocas e nações - com a finalidade de corroborar suas prescrições. A partir disso é possível o levantamento de um elemento importante: Hegel assume o risco de uma análise prescritiva em matéria de música, fragilizando sua abordagem filosófica.

Neste ponto é preciso que se entenda com base em que proposta teórica se pode apontar aqui o que seria essa "fragilidade". A partir do que foi até aqui demonstrado, pode-se tomar como certo que os desenvolvimentos iniciais da estética sempre esbarraram em dois problemas mais sérios. Em primeiro lugar, como se equilibrar entre duas dimensões com linguagens e códigos muitas vezes tão específicos (a filosofia e a arte) e, no caso da música, isso é ainda mais profundo: a codificação das estruturas grafadas em um código distante da linguagem verbal escrita (partitura) não raro seria um problema adicional, ocorrendo a partir dela muitas das demais possibilidades de exame estrutural (harmonia, melodia, texturas musicais, etc). Tem-se aqui a dificuldade de acesso do filósofo aos problemas estritamente poiéticos, dos quais poderia se deduzir aspectos só percebidos exteriormente sob o véu da aisthesis, o que está ligado às estratégias hegelianas na abordagem da música e ao modo como a ambiguidade kantiana

8 Não é demais relembrar que essa relação sempre foi um problema filosófico de primeira grandeza para a música. Os debates sobre esse problema, no entanto, foram mais acirrados quando realizados no âmbito da própria arte, não exatamente no âmbito da filosofia. Se é certo que na Poética de Aristóteles já se esboça uma reflexão sobre a

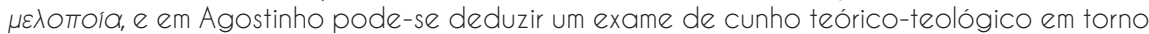
do prazer da música em detrimento da apreensão racional das palavras no cantochão, foi no âmbito da música que se aprofundou o pensamento sobre problema. Pode-se dizer, neste sentido, que essa questão é essencial em outros dois momentos: no século XVI, com o surgimento da Reforma Protestante, a questão do uso da palavra na música se torna um ponto focal numa proposta de renovação musical - Lutero não só acolhe o uso da língua vernácula para os hinos como simplifica a estrutura musical, dando primazia para a compreensão da palavra cantada na voz superior, a melodia. Nesse contexto "palavra" não é só o texto do hino e sim a palavra de Deus compreensivel por todos. Num segundo momento, ao fim do Renascimento italiano, se destacou uma querelle que pôs de um lado teóricos e músicos que consideravam, grosso modo, 1) a música como doadora de sentidos para palavra, portando mais importante e prevalente na conjunção entre as duas; outros, pretendendo um retorno ao "verdadeiro" espírito helênico, 2) postulavam que a música é apenas um suporte para a palavra, devendo ser um veículo discreto para o texto, cuja realização poética se deu no surgimento do estilo recitado em Florença.

\section{7}

REV. TULHA, RIBEIRÃO PRETO, v. 5, n. 2, pp. 259-287, jul.-dez. 2019 
se mantém em Hegel. Em segundo lugar, a consequente dificuldade em estabelecer uma delimitação epistemológica, a saber, quais os critérios e limites da análise estética e as formas de abordagem que o pensamento deve ter sobre as artes, o que pode ser notado na abordagem hegeliana da música quando o que está em jogo não é mais questão de especialista: justamente uma abordagem filosófica prescritiva em matéria de arte.

Quem com mais afinco se debruçou sobre o problema da delimitação epistemológica da estética foi o filósofo Luigi Pareyson (1918-1991). Segundo a sua teoria della formatività este problema pode assim ser apresentado: estética - reflexão geral sobre os fenômenos e a experiência da arte. Trata de categorias como "belo" ou "feio". Não é normativa, não legisla, não postula fórmulas e formas para o fazer artístico. Atua num terreno onde não se pretende a tomada de posição em questões da poética. É essencialmente uma disciplina filosófica, e, portanto, especulativa. É trabalho do filósofo; poética - conduta normativa na arte, com a proposição de manifestos ou programas, que pode ser tanto de um único artista, como de um grupo de artistas. Postura assumida em meio ao processo criativo em arte. Diz respeito ao fazer material e concreto da arte através da formação de obras. É prescritiva no sentido do que a arte deve ser. É trabalho do artista (PAREYSON, 1993 e 2001). É com base na teoria de Pareyson'9 que se pode apontar problemas na abordagem hegeliana da questão músicatexto, e com base nela se pode examinar este texto, chave importante para a construção deste estudo:

Se, todavia, o lado musical de uma tal obra de arte deve ser o essencial e o que predomina nela, então a poesia como poema, drama etc. não pode se apresentar com a reivindicação por validade particular. Em geral, no interior desta união entre música e poesia o predomínio de uma arte é prejudicial para a outra. Se, por conseguinte, o texto como obra de arte poética tem por si mesmo valor completamente autônomo, então ele pode esperar apenas um apoio

\footnotetext{
9 A teoria estética de Pareyson é uma das mais conhecidas e celebradas elaborações filosóficas contemporâneas sobre arte. Seria possivel explorar com mais precisão muitos aspectos pertinentes ao assunto estética x poética no sentido de pôr em questão a filosofia da música de Hegel. No entanto, isso traria a este estudo uma digressão por demais longa, acarretando o prejuizo do afastamento do objeto principal. Que se fique então apenas com a consciência do essencial.
}

\section{8}

REV. TULHA, RIBEIRÃO PRETO, v. 5, n. 2, pp. 259-287, jul.-dez. 2019 
insignificante da música; como, por exemplo, a música nos coros dramáticos dos antigos era um acompanhamento meramente subordinado. Mas se, inversamente, a música alcança a posição de uma peculiaridade por si mesma mais independente, o texto, segundo sua execução poética, pode então novamente ser apenas superficial e ficar preso aos sentimentos universais e às representações mantidas de modo universal. Elaborações poéticas de pensamentos profundos fornecem tampouco um bom texto musical bem como descrições de estados da natureza exteriores ou da poesia descritiva em geral. Cantos, árias de óperas, textos de oratórios etc. podem, por conseguinte, no que se refere à execução poética mais precisa, ser insuficientes e de uma certa mediocridade; o poeta, caso o músico deva conservar livre espaço de jogo, não deve querer ser admirado como poeta. Segundo este lado, particularmente os italianos tiveram grande habilidade, como, por exemplo, Metastásio e outros, ao passo que os poemas de Schiller, que também não foram feitos de modo algum para tal finalidade, se revelam como muito pesados e inaproveitáveis para a composição musical (HECEL, ano, p. 288).

Em termos mais diretos, pode-se dizer que as questões apresentadas são exemplares de uma complicada imbricação entre o aspecto normativo da produção das obras de arte e o pensamento filosófico sobre elas. Se não seria tarefa da filosofia estética postular quaisquer normas e prescrições no sentido de um programa artístico, permanecendo num âmbito não programático e não prescritivo, tratase então de uma fragilidade epistemológica o pensamento sobre arte em que poética e estética se confundem. Sendo normal que as primeiras elaborações filosóficas realizadas no âmbito de uma nova disciplina ainda não tivessem essa clareza epistemológica, nota-se que esta confusão é muito mais profunda do que se poderia imaginar. E é dela que surge a possibilidade de um pensamento filosófico-especulativo sobre o silêncio de Hegel sobre Beethoven e a possibilidade da resposta do compositor. Se a pergunta surge de um problema estético - as prescrições hegelianas reforçam por ausência a figura mais importante do período, que jamais é citado nos fartos exemplos de como a arte deve ser -, a resposta pode ser dada na poética: se para Hegel a poesia de Schiller é exemplo de incompatibilidade na relação música-texto, Beethoven pode então provar o contrário no âmbito da obra musical. E, de fato, Hegel insiste numa normativa da possibilidade

\section{9}

REV. TULHA, RIBEIRÃO PRETO, v. 5, n. 2, pp. 259-287, jul.-dez. 2019 
poiética da relação música-texto, e de modo ainda mais contundente, a poesia de Schiller se mantém como objeto:

A exigência principal que tem de ser feita, no que se refere a um bom texto, consiste no fato de que o conteúdo tenha em si mesmo consistência verdadeira. Com algo em si mesmo raso, trivial e absurdo não se pode elaborar artisticamente nada que é musicalmente válido e profundo. Mas por mais que o compositor possa torná-lo picante e temperado, de um gato assado não se faz uma empanada de lebre. Em peças meramente melódicas, sem dúvida o texto é no todo menos decisivo; todavia também elas exigem um Conteúdo verdadeiro das palavras. Por outro lado, contudo, este conteúdo não pode ser novamente de profundidade demasiadamente pesada e filosófica, como, por exemplo, a lírica de Schiller, cuja amplidão grandiosa do pathos sobrevoa a expressão musical dos sentimentos líricos (HECEL, 2002, p. 329-330).

Este também é um texto chave do pensamento de Hegel. Na medida que o confrontamos com a questão epistemológica já verificada, vemos que se trata quase de um manifesto. Mas aqui se pode ir mais além, o que é importante para que se entenda os desdobramentos deste estudo. $\bigcirc$ que o filósofo sugere, grosso modo, pode ser compreendido assim: para que uma composição que relaciona música e poesia (árias operísticas, lieder) seja bem-sucedida, é preciso uma espécie de "equilibrio" entre complexidades semântico-estruturais das duas formas de arte ${ }^{10}$. Este equilibrio seria alcançado, segundo Hegel, quando uma das formas de arte assumisse um papel de condescendência em relação à outra no que diz respeito a essas complexidades: uma música estruturalmente

10 A partir de uma análise dentro do contexto mais amplo dos Cursos, é possível deduzir que este "equilíbrio" tem a ver não só com as possibilidades semânticas de música e texto. Hegel, de fato, não deixa claro em que sentido exato as qualidades que contribuem para consistência das elaborações se relacionam, produzindo uma resultante que pode ser mais superficial ou profundo, mais ou menos poética ou artística, com mais peso ou mais rasa, com mais ou menos pathos. Fica claro, por outro lado, que Hegel considera todos estes adjetivos subsumidos a uma ideia de autonomia: se uma poesia bastar-se por si mesma, neste conjunto de interações que se consubstanciam num complexo, terá pouca serventia para música, e assim vice-versa (no caso uma música que se bastaria como música instrumental). Doravante, opta-se aqui pelo uso da expressão complexo em sentido estrito: complexidade diz respeito a esse conjunto de interações que pode ser deduzida do modo como expressa Hegel as suas preocupações, resultantes da possibilidade de subjugamento de uma arte pela outra.

\section{0}

REV. TULHA, RIBEIRÃO PRETO, v. 5, n. 2, pp. 259-287, jul.-dez. 2019 
complexa se relacionaria melhor com certo tipo de literatura mais simples (embora nunca banal). Se o texto for mais profundo, mais complexo do ponto de vista filosófico e semântico, o melhor é uma música mais simples, menos autônoma. Pode-se deduzir que Hegel imagina que poderia haver uma confusão ou mesmo anulação dos afetos ou dos pathos em jogo. A ideia hegeliana é bem interessante, embora, de certa maneira, não seja original: a discussão sobre a relação entre música e texto enveredou por algo parecido na passagem do século XVI para o XVII, quando o que estava em discussão também aludia a um jogo de complexidades semânticas e afetivas. A novidade em Hegel, e também a fragilidade de sua posição, reside - em conformidade com a base teórica adotada neste estudo - no caráter prescritivo de sua abordagem, até mais do que os músicos, teóricos e filósofos do início século XVII, cujas elaborações às vezes se mantêm em um notável patamar de abstração. Hegel chega a prescrever inclusive o que seria um limite para o compositor: justamente pôr em música a poesia de Schiller.

\section{O estranho silêncio de Hegel}

Vê-se que a leitura da parte dedicada à música nos Cursos reflete de modo exemplar três tipos de situação: possibilita o exame desta arte naquele período; permite analisar a condição da própria estética musical no início do romantismo; permite a compreensão das relações sociais e de recepção tanto da arte musical como dos próprios escritos hegelianos em determinado período histórico e geográfico, tornando-se um documento fundamental em vários sentidos. Quando este documento é cruzado com a crítica musical de épocall à obra de Beethoven, têm-se elementos ainda mais reveladores. Revelam, por exemplo, que à época das preleções de Hegel, o compositor já era o mais influente artista europeu e gênio reconhecido por público e crítica. Levando em conta todas essas situações, torna-se realmente inusitada a ausência de Beethoven em suas preleções. Uma forma de "ausência explicita", quando o que temos é um panteão dos grandes:

1 I As referências à crítica contemporânea de Beethoven partem de uma leitura das grandes compilações de SENNER, WALLACE e MEREDITH (2001, 2017), que reuniram inúmeros documentos da crítica musical de época, o que dá uma dimensão bastante precisa da recepção da obra de Beethoven, em especial as mais tardias. 
Desta espécie é a música verdadeiramente ideal, a expressão melódica em Palestrina, Durante, Lotti, Pergolesi, Cluck, Haydn, Mozart. O repouso da alma não se perde nas composições destes mestres; na verdade, a dor igualmente se expressa, mas ela sempre é dissolvida, a justa medida clara não se dispersa em nenhum extremo, tudo permanece firmemente junto numa forma dominada, de modo que o júbilo nunca degenera num furor tumultuoso e fornece ele mesmo ao pranto o mais sereno descanso (HECEL, 2002, p. 324).

Tomando as próprias palavras de Hegel no seu longo estudo sobre a música, permanece então algo que têm chamado a atenção de todos desde que os Cursos foram publicados, em especial quando pensados dentro do contexto histórico, artístico e filosófico já exposto: por que, ao citar em seus exemplos diversos compositores e mesmo obras importantes, Hegel não inclui nenhuma referência a Beethoven, reconhecidamente o mais influente e notável compositor/pensador da música atuante no seu mesmo contexto histórico-geográfico e ambiente intelectual? Posta a situação da filosofia estética em relação à música no contexto hegeliano; examinada a possivel e pregnante influencia kantiana nesse contexto e o modo como ela se transforma num outro tipo de desconfiança com relação à música instrumental, cujo interesse não seria universal; analisados os desdobramentos da confusão epistemológica estética x poética; e sendo Beethoven um compositor representativo da autonomia da arte musical - talvez o primeiro - e um indubitável ponto culminante da música dita absoluta, representante de um grande avanço especialmente nos gêneros da música instrumental: tem-se já delineada uma possibilidade conjuntural do significado do silêncio de Hegel. Em outras palavras, Beethoven justamente seria representativo, e maior promotor, de um caminho para música que o filósofo, possivelmente, olhava com desconfiança. Desenvolvimentos ulteriores, cruzamentos e comparações que serão obtidos neste estudo, poderão ainda reforçar esta tese.

Mas, à esta altura, é válida uma pergunta consequente: o silêncio de Hegel sobre Beethoven é de fato um silêncio? Pode-se pensar que não. É possivel deduzir isto da ênfase quase sempre negativa de Hegel no sentido de engrandecer essa música ideal, produzida pelos compositores desse panteão, (aqui, com grifos especiais): "o repouso da alma" que não se perde na obra deles; "a justa medida clara" que "não

\section{2}

REV. TULHA, RIBEIRÃO PRETO, v. 5, n. 2, pp. 259-287, jul.-dez. 2019 
se dispersa em nenhum extremo", “o júbilo" que "nunca degenera num furor tumultuoso". Identificar uma resposta nas entrelinhas pode preencher este silêncio de significado. Neste sentido, o recurso à leitura da crítica às obras de Beethoven pode trazer ainda maior consistência à afirmação de que o silêncio de Hegel encontra Beethoven nas entrelinhas. Os adjetivos usados por Hegel para dizer o que os compositores ideais não fazem são comumente usados para definir a expressão musical de Beethoven, mesmo nos dias de hoje. Para que não se incorra no risco de anacronismo, tomando somente a canonização das expressões corriqueiras usadas para qualificar a obra do compositor, basta a leitura da crítica contemporânea ao compositor, preferencialmente a das sinfonias e obras mais antigas, quando o compositor não era ainda tão claramente considerado a grande expressão musical do período. Uma análise rápida desses escritos apresenta alguns elementos importantes para este estudo. A crítica da época é, desde suas primeiras sinfonias, geralmente favorável, reconhecendo os prodígios, a originalidade e genialidade do compositor. Porém, tanto quando favorável como quando desfavorável, ela muitas vezes põe foco justamente em pontos parecidos, igualmente usados para elogiá-lo ou depreciá-lo; diga-se que termos bem afinados com aqueles que Hegel expõe depreciativamente ao falar de determinadas questões musicais.

Muitos são os desmentidos da história da música que apontaram na poética de Beethoven a barbárie musical das dissonâncias, os choques sonoros ruidosos, a ausência de sentido, os extremos tumultuosos, a falta de unidade, medida e clareza, a incapacidade de julgamento estético, os elementos desagradáveis, a duração interminável das obras (UALLACE, 2017), enfim, muitas vezes numa terminologia bastante similar àquela usada por Hegel para falar sobre vários usos musicais que não ocorrem nas obras dos grandes. E o mais interessante é que a esmagadora maioria da crítica contemporânea de Beethoven o louva, em parte, por esses mesmos efeitos, considerados então como originais, pertencentes a um temperamento intempestivo, mas genial. É quase impossivel não ter a imaginação estimulada quando comparados o texto hegeliano sobre o fundamento dramático-musical e as críticas de época à única ópera de Beethoven (a primeira versão de Fidelio é sem dúvidas sua obra de pior recepção):

Igualmente importante é, além disso, a relação na qual devem aqui surgir, por um lado, o característico, por outro lado, o melódico. A exigência principal parece-me ser nesta

\section{3}

REV. TULHA, RIBEIRÃO PRETO, v. 5, n. 2, pp. 259-287, jul.-dez. 2019 
relação a seguinte: a vitória sempre há de ser atribuída ao melódico, enquanto a unidade concentradora, e não à separação em traços característicos singularmente dispersos. Assim, por exemplo, a música dramática atual procura muitas vezes seu efeito em contrastes violentos, na medida em que comprime paixões opostas, lutando de modo plenamente artístico, em um e mesmo desenvolvimento musical. Ela expressa, por exemplo, assim a alegria, o casamento, a pompa festiva e nisso insere igualmente o ódio, a ira, a inimizade, de modo que entre o prazer, a alegria, a música dançante se agitam ao mesmo tempo a rixa impetuosa e a mais repugnante cisão. Tais contrastes do dilaceramento, que nos lançam sem unidade de um lado para o outro, são tanto mais contra a harmonia da beleza quanto mais unem imediatamente em caracterização aguda coisas opostas, onde então não se pode mais falar do gozo e do retorno do interior para si mesmo na melodia. Em geral, a união do melódico e do característico traz consigo o perigo de facilmente ultrapassar, segundo o lado da descrição mais determinada, os limites suavemente traçados do belo musical, particularmente quando se trata de expressar a violência, o egoísmo, a maldade, a impetuosidade e outros extremos de paixões unilaterais. Tão logo a música aqui se entrega à abstração da determinidade característica, ela é quase inevitavelmente conduzida para desvios, a penetrar na agudeza, no que é duro, inteiramente não melódico e não musical e mesmo a abusar do desarmonico" (HECEL, 2002, p. 332).

E como se encontram espalhadas em publicações daquele período, há ainda sentenças vizinhas, como, "foi desagradável, devido às incessantes dissonâncias (...), e é mais uma afetação do que a verdadeira arte", e mesmo "até agora, Beethoven havia tantas vezes prestado homenagem ao novo e ao estranho às custas do belo". Ou algumas muito mais contundentes, como a que segue:

(...) a falta de sentido das partes faladas anulava completamente ou quase sempre o belo efeito das partes cantadas. $\bigcirc$ Sr. B. não possui um julgamento estético elevado em sua arte, pois entende como expressar extraordinariamente bem as emoções que estão nas palavras a serem definidas, mas ele parece não ter a

\section{4}

REV. TULHA, RIBEIRÃO PRETO, v. 5, n. 2, pp. 259-287, jul.-dez. 2019 
capacidade de examinar e julgar o texto com relação ao efeito total (SENNER, 2001, p. 179).

Curiosa por si só, a leitura das críticas, quando comparadas aos escritos de Hegel, traz à presente hipótese não só maior consistência como faz crescer também a sombra de Beethoven sobre as preleções de Hegel. Se o maior e mais influente compositor (e pensador da música) de seu tempo não merece uma só menção do maior filósofo, aparece, no entanto, amplamente criticado nas entrelinhas e, não por acaso, isso ocorre sempre que o filósofo desliza para a prescrição, se mantendo mais no âmbito da poética do que da estética.

\section{Beethoven e sua obra-refutação}

Se até agora pôde ser verificada a possibilidade de se especular com alguma solidez sobre o silêncio de Hegel com relação a Beethoven, pode-se então direcionar este estudo a uma região mais interessante e movente, onde se procurará estabelecer uma narrativa possivel sobre a posição de Beethoven.

Se desde a publicação póstuma dos Cursos de Estética a ausência do compositor foi notada, formular hipóteses mais específicas sobre os porquês jamais ocorreu seriamente. As razões são óbvias: retroceder aos anos em que Hegel fazia as suas preleções e calcular os impactos de sua recepção entre os compositores já seria tarefa especulativa difícil. Cruzar esses elementos com a possibilidade de examinar a sua recepção por Beethoven torna tudo mais movediço.

De fato, é impossivel dar respostas precisas para algumas questões. Mas pode-se notar que um exame mais acurado no sentido da presente hipótese enriquece a abordagem dos textos de Hegel. Se analisadas as possibilidades em torno de Beethoven, buscando aquilo que se poderia hipoteticamente considerar o (não)diálogo entre os dois, é possivel um resultado repleto de elementos interessantes para o pensamento sobre a relação entre música e filosofia, para muito além do objeto escolhido para este estudo.

No ponto em que agora se encontra o desenvolvimento deste estudo é importante que se rememore como vem se configurando a 
hipótese: 1) Toma-se o silêncio de Hegel sobre Beethoven como proposital - verificou-se inclusive o que, para além deste silêncio, pode constar nas entrelinhas 2) Beethoven pode ter compreendido a fragilidade de determinado aspecto da estética hegeliana tentando respondê-la, ou revidar o desdém do filósofo no campo específico da arte, em especial em sua última sinfonia. 3) Ao respondê-lo, demonstrando a fragilidade de uma tese específica, Beethoven paradoxalmente comprova outra.

Na forma como se desenvolveu o pensamento até aqui, tal construção não pôde prescindir de ser ao mesmo tempo um exame no campo da filosofia em contraste com o campo da poética (o que seria a tal fragilidade na estética de Hegel) e da inserção da estética em determinado contexto histórico e cultural (em que contexto se dão os dilemas). Agora é necessário que se parta de um exame mais afeito ao campo da arte, tendo a poética como plano de expressão (como responde Beethoven no âmbito da poíesis). Por isso se caminha agora para a seguinte questão: ciente do desdém hegeliano sobre si, e ciente da prescrição de Hegel em suas preleções - que sacramentam a impossibilidade ou inviabilidade de associar música à poesia de Schiller -, teria Beethoven tentado provar o contrário, não só musicando a poesia de Schiller como inserindo-a no contexto de um gênero de música pura, justamente aquele de que Hegel desconfia? É possivel. E essa mera possibilidade é fascinante. No entanto, o que se propõe neste estudo vai se perfazendo mais como uma especulação filosófica, que persegue uma parábola possivel por dentre os labirintos factuais, do que propriamente a resolução acadêmica de problemas a partir de evidencias incontestáveis.

Se de fato temos o magistral revide beethoveniano, para que se mantenha a honestidade com o leitor, é preciso demonstrar quais seriam os problemas desta admissão, oriundas das impossibilidades de conclusões, já que premissas inconfiáveis. Para que a abordagem da questão hegeliana sugira a reposta beethoveniana como fato, será preciso cruzar datas, atribuir importâncias, imaginar certas situações. Mas se verá que, mergulhada na areia movediça das probabilidades cambiantes, se pode estabelecer chaves hermenêuticas com importantes efeitos colaterais para o pensamento sobre música e filosofia, o que significa que mesmo que se reduza a uma fantasia filosófica, o processo de pensar estas relações já é válida per se.

\section{6}

REV. TULHA, RIBEIRÃO PRETO, v. 5, n. 2, pp. 259-287, jul.-dez. 2019 
E eis exposto o campo movente desses cruzamentos, resumido em seus principais problemas: os Cursos de Hegel foram publicados postumamente, a partir de suas preleções, em 1835. Tais preleções, apesar do sucesso incontestável de divulgação em larga escala das ideias do filósofo, podem jamais ter chegado aos ouvidos - sem intenção de ironia - do compositor. As preleções basilares que apresentaram as ideias estéticas do filósofo são de 1818 e 1820, mas foram aprofundadas até 1826, tendo a si ajuntado suplementos até 1829. Sabe-se que a Nona Sinfonia de Beethoven - onde se encontra o possivel revide do compositor - foi composta entre 1817 e 1824, havendo, portanto, apenas uma pequena janela de intersecção temporal para as possibilidades que aqui se aventam. É nesta janela que um Beethoven já consciente do desdém de Hegel, e sabedor de suas prescrições e restrições sobre o uso da poesia de Schiller em música, poderia ter pensado em respondêlo de forma tão contundente, através de uma sinfonia. A Nona seria então uma obra-refutação. Chega-se então a uma proposta inusitada: a grande inovação da última sinfonia de Beethoven - celebrar a união das artes irmãs (música e poesia) - teve motivações filosóficas, pretendidas como refutação às hipóteses de Hegel.

Malgrado baixas probabilidades suportem essa proposta, a favor tem-se que o desenvolvimento da Nona Sinfonia coincide de forma fascinante com o percurso das preleções. Porquanto seja difícil que Beethoven tenha tido acesso a qualquer conteúdo escrito, não é difícil que ele tenha sabido do desdém de Hegel em relação a si, dado não só a influência aguda do filósofo no pensamento germânico de então, como também sua influência sobre o próprio compositor ${ }^{12}$, o que aponta para a importância de se pensar o que aqui se quer pensar. E mais: recentemente a descoberta de um manuscrito base das preleções ${ }^{13}$ mostra que em 1822/23 as ideias hegelianas sobre arte já estavam muito próximas do acabamento ideal, cujo conteúdo "completo" seria publicado nos Cursos, o que estimula ainda mais a especulação sobre as questões aqui levantadas, já que não só confirma a janela como a localiza para, com certeza, antes do termino da sinfonia.

12 Importante rememorar a epígrafe deste estudo, onde Tostes aponta a influência hegeliana sobre Beethoven em sua sonata op. 90 a partir de um estudo do musicólogo alemão Werner Korte, cuja referência não é citada.

13 A descoberta recente do manuscrito das preleções de Hegel na biblioteca Victor Cousin na França, publicado por Dario Giuliano em 2017, é um importante documento para o estabelecimento cronológico da elaboração das preleções. Em HECEL, 1835 [2017]. 
Ditas todas essas coisas, seria possivel encerrar essa curiosa especulação filosófica por aqui, no apego dos aspectos que corroboram a tese construída. No entanto, é preciso contrapor ainda outros elementos, para que avance ainda mais um movimento dialético de exposição de argumentos do qual sínteses também importantes possam vir à tona. Por isso, é preciso dizer que apesar das possibilidades surgidas da identificação daquela janela, vê-se que os pontos de apoio ainda permanecem por demais movediços, às vezes quase obrigando uma especulação pura, afinal, certas perguntas são de resposta impossivel: as questões especificas sobre música apresentadas por Hegel chegaram a Beethoven antes ou depois da inclusão da poesia de Schiller na sinfonial4? Também não é possivel saber qual o nível de impacto em Beethoven dos escritos sobre música quando foram apresentados apenas em sua forma oral, nem quando ele ocorreu, para termos certeza se o compositor pode ter ou não sabido do seu conteúdo na forma como ele parece ter sido apresentado. E mesmo que fosse sabido, se mantém impossivel um nível razoável de certeza factual quanto ao momento do surgimento da ideia de incluir a Ode de Schiller na sinfonia.

Como o já demonstrado, se consideradas as informações de seu primeiro biógrafo, as possibilidades da janela receberiam um importante ponto de apoio no sentido de corroborar a hipótese da Nona como obra-refutação. Mas novos documentos e manuscritos têm aparecido ao longo dos anos demonstrando que muito dos relatos de Schindler são, como toda biografia, literatura quase ficcional, dizendo às vezes mais sobre o biógrafo do que sobre o biografado. E infelizmente ainda as informações sobre o processo de composição da Nona, no sentido de uma cronologia, se reduzem quase que exclusivamente ao relato deste que tem sido veemente contestado.

14 É bastante conhecido o relato de seu biógrafo Anton Felix Schindler (1795-1864), e por inverídico ou exagerado que ele possa ser, corroboraria a tese deste estudo, uma vez que localiza a inclusão da poesia na sinfonia para depois de elaboradas as preleções em suas configurações mais derradeiras. De qualquer maneira e apesar disso, se mantém válido lembrar: “(..) em fevereiro de 1824, este colosso foi concluído. (...) Terminado o quarto tempo, [Beethoven] começou uma luta singular. Tratava-se de encontrar um modo conveniente de introduzir a ode de Schiller. Um dia, ao entrar em seu aposento, Beethoven me gritou: 'Encontrei. Encontrei'. E me mostrou o rascunho no qual estava escrito: 'E agora cantemos o lied do nosso imortal Schiller'. Esta frase foi depois substituida por aquela em que o solista anuncia o início da ode: 'Amigos, mudemos de tom agora e entoemos cantos de alegria" (SCHINDLER, 1900 [1835], p. 93).

\section{8}

REV. TULHA, RIBEIRÃO PRETO, v. 5, n. 2, pp. 259-287, jul.-dez. 2019 


\section{Beethoven: proprietário de um cérebro ${ }^{15}$}

Sem dúvidas, a dificuldade de acesso à relatos confiáveis - em especial quando se cruzam dois campos na inteireza de suas possibilidades - deve ter desencorajado ao longo do tempo um pensamento mais sério sobre a relação Hegel-Beethoven. Mas a narrativa construida na forma deste estudo demonstra que é justamente esse aberto de possibilidades que torna mais atrativas abordagens dessa natureza. Além disso, especular sobre uma possivel motivação para a invenção de uma das obras mais importantes de toda cultura ocidental vale um esforço de pensamento ${ }^{16}$.

Se colocada em perspectiva a trajetória feita até aqui, é difícil considerar apenas coincidência ${ }^{17}$, com relação à estética de Hegel, - curioso fato de que o compositor tenha escolhido justamente a poesia de Schiller para realizar uma das mais notáveis audácias da história da música, ao implementar, pela primeira vez, o uso de texto (consequentemente da voz humana) numa sinfonia, gênero puramente instrumental. Tomados todos os cruzamentos até aqui realizados, mesmo com toda a gama de variações probabilísticas envolvidas, é valido expor mais uma vez a síntese do percurso deste estudo, que se aos mais céticos se aproximará mais de uma "fantasia filosófica", aos entusiastas dará margem para que a discussão se desdobre ainda mais. Numa quase-conclusão vale a auto sentença de Beethoven, como sendo "proprietário de um cérebro". Aliás, é o conhecido temperamento do compositor, a maior parte das vezes irônico e irascível, que nos permite um exame do problema: quando o mais influente e admirado filósofo do seu tempo o desdenha em suas preleções (e o crítica nas entrelinhas), dando primazia a muitos outros compositores em detrimento de si, é

15 Alusão ao modo como, ironicamente, Beethoven responde a um cartão de seu irmão, que atribuía a si o título de "proprietário de terras".

16 Novamente merece menção quem primeiro pensou que tal estudo pudesse ser realizado, Tostes: "E a gente pergunta sem querer: Por que logo a Ode de Schiller? Os libretistas sobravam naquela época e todos os grandes, de Bach a Mozart, recorriam aos seus préstimos literários. Não seria um revide beethoveniano à afirmação do pontífice da filosofia? Eis um ponto que a crítica poderia investigar com base nessa interessante coincidência" (WACNER, 1987, p. 7).

17 A tese da "coincidência" pode ser reforçada pelo fato de que talvez Beethoven já pensasse em compor um Lied sobre poesia de Schiller em sua juventude. Obviamente que isso não eliminaria a possibilidade de que o comentário hegeliano possa ter estimulado um projeto anterior não realizado. Mas assumindo a não confiabilidade do relato de Schindler mesmo quando contrário, também se deve assim assumi-lo quando está a favor da tese deste estudo. Por isso a ideia do revide não pode e nem deve ser descartada.

\section{9}

REV. TULHA, RIBEIRÃO PRETO, v. 5, n. 2, pp. 259-287, jul.-dez. 2019 
preciso uma resposta à altura desse silêncio. Beethoven é perspicaz o suficiente para saber que, se as elucubrações filosóficas de Hegel o elevaram ao patamar mais alto do pensamento germânico, ele peca em matéria de música. E peca justamente por enveredar nesse campo propositivo de como a arte deve ser, explorando aquilo que, justificativa do próprio filósofo, ele não domina - os problemas de poética musical. E seu maior pecado é, dentre todas as normativas, a asseveração de que o pathos da poesia de Schiller excederia as possibilidades da música, e por isso não seria apropriada como texto musical. Então é no campo da arte, e não da filosofia, que Beethoven responde ao programa hegeliano mostrando, pleno em seu mister, que não só a poesia de Schiller pode servir à música, como ela dá vazão a uma proposta revolucionária, no mais complexo e monumental gênero da música sinfônica. A Ode an die Freude de Schiller torna-se, então, o finale da Nona Sinfonia de Beethoven, até hoje aclamada como um dos mais perfeitos exemplares da música ocidental. Ao fim e ao cabo, teria Beethoven provado que o programa hegeliano estaria equivocado? Afinal, refuta o filósofo quando a um só passo usa o poema de Schiller - colocado por Hegel como um limite para a música - fazendo-o ainda no âmbito do mais monumental e complexo gênero musical do século XIX, propondo um casamento entre música e poesia que refuta a abordagem frágil de Hegel. Em outras palavras, Beethoven teria provado que se pode, em matéria de relação música-texto, entremear as complexidades da música e da palavra, mesmo que ambos possuíssem niveis muito profundos de pathos, semântica e estrutura. Não por acaso, teria usado a Ode de Schiller num gênero de música puramente instrumental, em que a música deve se bastar por si mesma: uma autêntica ironia, configurada como resposta nos signos da música que Hegel desconfia. Beethoven, assim, teria dado também uma resposta ao dilema kantiano, tornando indiferentes de um ponto de vista artístico a música pura ou acompanhada/suportada pela palavra. Desse modo se perfaz a Nona como obra-refutação.

Lido assim, esse panorama demonstraria Beethoven não apenas como um músico-filósofo, mas também o vencedor desta querelle muito peculiar. Mas se Beethoven vence por ter identificado na estética hegeliana essa fragilidade (a confusão entre poética e filosofia), dando-the uma resposta visceral no campo da poética, só poderia estar sacralizada sua vitória após uma análise também no campo da poética. Para tanto, é apropriado que este estudo avance em direção ao rompimento de mais uma camada hermenéutica. $\bigcirc$ uso da Ode de Schiller como finale da Nona, analisado do ponto de vista da poética

\section{0}

REV. TULHA, RIBEIRÃO PRETO, v. 5, n. 2, pp. 259-287, jul.-dez. 2019 
musical, teria refutado ipso facto a hipótese hegeliana do cruzamento de complexidades?

\section{Epílogo: O revés do revés}

Como já demonstrado neste estudo, as expressões que melhor sintetizariam a teoria hegeliana sobre a relação entre música e palavra poderiam ser complexidade e autonomia. Pode-se deduzir de seus escritos que a chave poiética para que a construção de uma obra que pressuponha essa relação logre sucesso é a justa medida no equilíbrio entre complexidades da música e da palavra e o grau de autonomia de cada uma delas. A rigor, música complexa e mais autônoma se relacionaria melhor com maior simplicidade (não banalidade) poéticoliterária. Música simples e menos autônoma serviria melhor aos textos mais complexos, poéticos. Hegel não desenvolve essa ideia com rigor. Mas vêse que há uma clara tentativa de prescrever melhores possibilidades de que, na relação entre as artes, uma não subjugue a outra. Para Hegel, a poesia de Schiller seria um limite, ou seja, traria a impossibilidade de realização desse projeto de equilibrio. A partir da hipótese aqui levantada, ao utilizar a poesia de Schiller em sua sinfonia de forma tão eficaz, Beethoven teria refutado a tese hegeliana.

Mas se de fato o método da presente proposta reside no exame das imbricações entre poética e estética, seria de todo desejável que se verificasse em que sentido se pode falar de complexidade e autonomia musical na sinfonia de Beethoven.

Por monumental que seja a Nona, com seus imponentes 80 minutos de duração divididos em 4 movimentos, na qual o compositor lança mão de uma diversidade impressionante de recursos composicionais, tipos de textura musical, inovações harmônicas e formais; por profunda que seja semanticamente e autônoma enquanto arte puramente musical; por complexo que seja o encadeamento de eventos musicais que desde o início da sinfonia prepara condições consistentes para que a introdução da voz através do poema de Schiller não soe como um elemento alienígena no último movimento; por difícil que tenham sido os oito anos da costura artesanal da peça, em especial a própria introdução da Ode de Schiller: do ponto de vista da poética podese ainda indicar uma irônica virada nesta relação da sinfonia com o programa hegeliano. 
Demonstrar essa virada em todos os seus pormenores demandaria uma análise técnica mais profunda, já muito realizada fora do âmbito da estética, em especial pelas disciplinas de análise musical que partem de estratégias de abordagem empírico-matemáticas. Estas, em parte, estariam acessiveis somente aos especialistas e ainda assim não responderiam às perguntas dentro do âmbito aqui proposto. Por isso aqui se dará uma formulação mais simples.

Por musicalmente exaustiva que seja uma obra da magnitude da Nona, essa complexidade se dá no encadeamento de eventos: temas musicais que devem ser desenvolvidos, a estrutura formal que, no classicismo, é composta por relações de consistência tanto na formação micro - da construção dos motivos melódicos à concatenação de motivos na formação de um grande tema melódico - e macro: o modo como essas relações possuem um ideal de proporcionalidade, e os temas e motivos que se movem sobre os encadeamentos harmônicos e se distribuem no tempo enquanto discurso articulado. É certo que pôr junto tudo isso em uma obra demanda um esforço e uma energia inventiva que resultaram numa obra monumental. No entanto, em música é possivel - devido ao seu caráter eminentemente matemático - reduzir os parâmetros de modo que se desnudem certos elementos essenciais. No caso da poética beethoveniana, é possivel reduzir toda obra sinfônica a noções mais simples, como melodia acompanhada, por exemplo, de modo que se verifique, por detrás de artifícios texturais e de instrumentação, o que está no âmago da composição. A obra não continua sendo exatamente a mesma obra, é certo ${ }^{18}$, mas apenas no sentido em que um corpo inanimado não é mais uma pessoa, mas se

18 Para o não especialista é importante a compreensão de que, grosso modo, o processo de redução consiste num procedimento composicional comum no universo da música sinfônica, em que uma obra de instrumentação vasta - como uma sinfonia ou uma ópera, por exemplo -, onde inúmeros instrumentos e vozes atuam, é reescrita frequentemente para piano ou piano e voz (ou instrumento solista). São múltiplas as finalidades: didático-pedagógica (um pianista pode tocar uma obra sinfônica em seu instrumento; um musicólogo acessa ou demonstra mais facilmente os parâmetros de uma obra sinfônica); para viabilizar ensaios (o piano cumpre o papel de orquestra reduzida para acompanhar os cantores nos ensaios de uma ópera ou musical, de modo que não seja preciso sempre uma orquestra com muitos músicos em todos os ensaios; um solista pode ensaiar um concerto com acompanhamento do piano antes de iniciar os ensaios com a orquestra etc.). $\bigcirc$ inverso deste procedimento é o procedimento composicional onde uma obra composta originalmente para um instrumento (o piano, por exemplo) é instrumentada/orquestrada de modo a se "expandir". Exemplos paradigmáticos são as Variações Holberg de Edvard Grieg (realizado pelo próprio compositor) e Quadros de uma Exposição de Modest Mussorgsky, cuja versão "expandida" é de Maurice Ravel.

\section{2}

REV. TULHA, RIBEIRÃO PRETO, v. 5, n. 2, pp. 259-287, jul.-dez. 2019 
descobrem os mesmos órgãos se dissecado. Se assim fizermos no trecho especifico em que emerge a Ode a Alegria, chegaremos a isso:

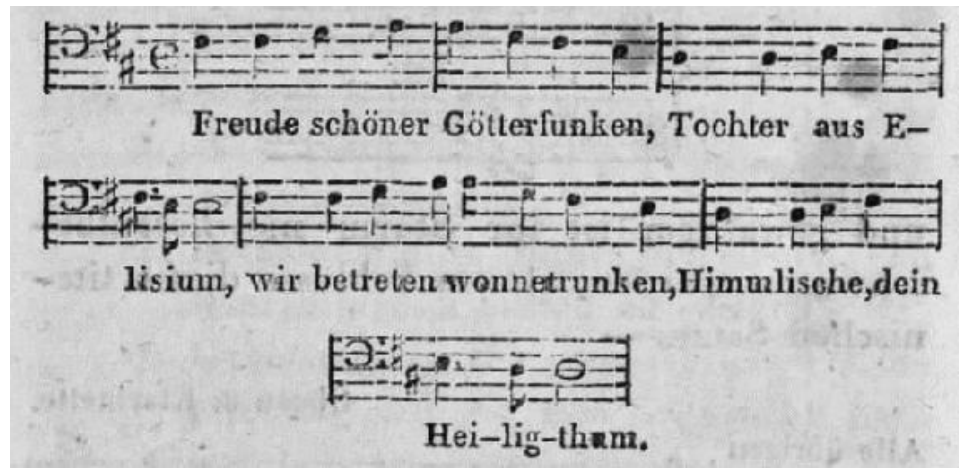

Figura 1 - Excerto extraído de SCHINDLER, 1900 [ 1835]

Obviamente este tema se desdobra entre solistas, coro e orquestra em possibilidades bastante intrincadas. Mas, mesmo para aqueles que não compreendem este código de grafia, a partitura, deve ficar claro que se trata de uma melodia bastante simples. Na verdade, é tão simples e cantável, que o maestro Hebert von Karajan rearranjou-a em 1972 para se tornar o hino da União Europeia ${ }^{19}$. Em outras palavras, este tema se presta à ideia do texto reforçando o caráter de hino, portanto algo que possa ser cantado comunitariamente, que possa ser memorizado instantaneamente. Não por acaso tornou-se uma das mais conhecidas melodias do mundo, acessivel mesmo a quem falta qualquer estudo ou conhecimento formal de música ${ }^{20}$. Ela é, talvez, o mais simples dentre todos os temas de obras sinfônicas consideradas maiores na história da música, justamente por ser absolutamente trivial ritmicamente e completamente diatônico, baseado em uma única escala

19 Em 1972 o tema musical composto por Beethoven foi oficialmente adotado pelo Conselho da Europa. O maestro alemão Herbert von Karajan realizou os três arranjos oficiais: um para piano, um para instrumentos de sopro e outro para orquestra. Em 1985 a União Europeia adotou o mesmo símbolo com todos os significados a ele inerentes.

20 Não é surpreendente que a torcida da Coreia do Sul entoasse com muita eficácia essa melodia com as palavras 대한민국 (Daehanmingug: Coréia do Sul) na Copa do Mundo de Futebol de 2002. 
maior. Do ponto de vista harmônico, o acompanhamento também é, consistente com o caráter da melodia, bastante simples. Ao modo de um acompanhamento coral, acordal, todo o efetivo orquestral pode se reduzir a isto:
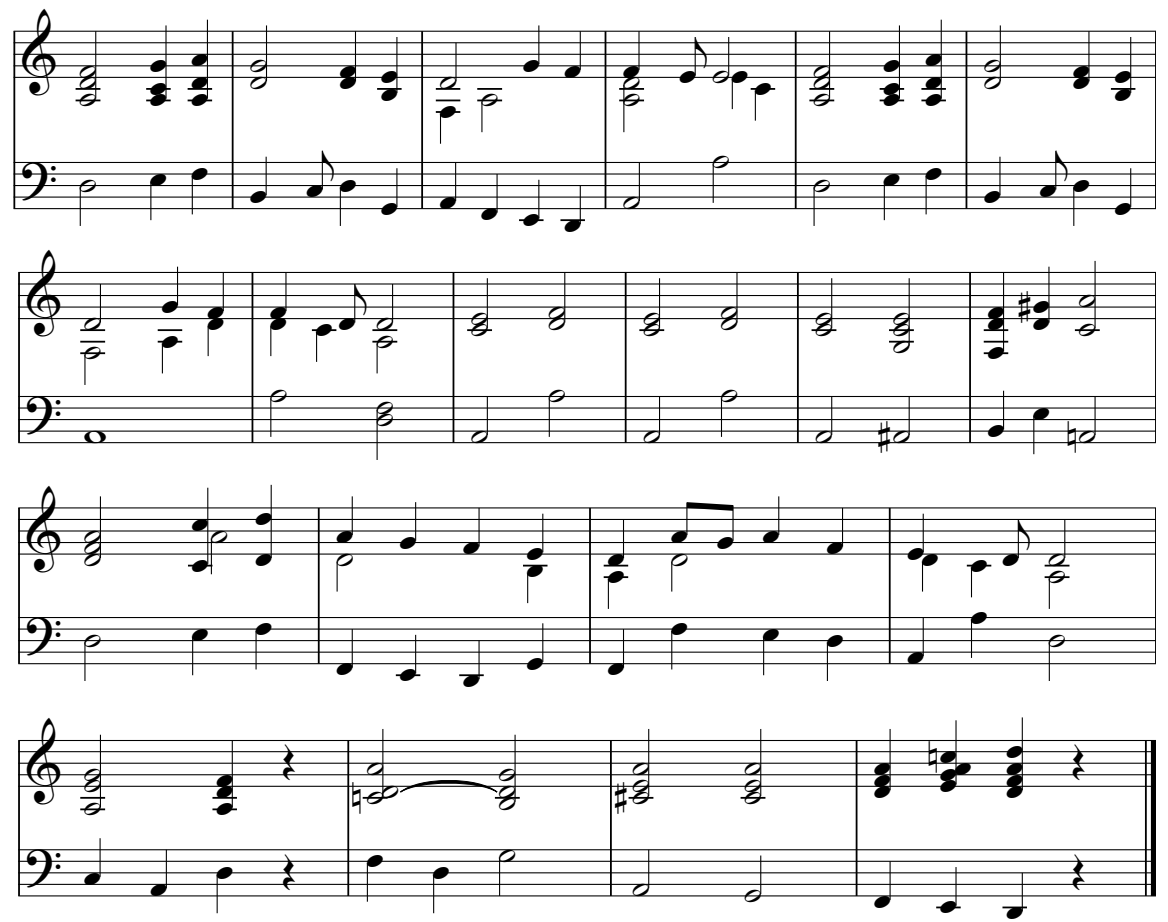

Figura 2 - redução minha

Obviamente os desdobramentos do tema principal do hino e sua concatenação com temas expostos em todos os movimentos anteriores também são perpassantes da continuidade do poema de Schiller, ganhando em alguns momentos em complexidade técnica (as partes solistas e corais são de fato muito difíceis), profundidade e pathos, porém sem nunca perder o caráter do tema principal, de hino comunitário, simples e direto. 
E o que isso quer dizer? Talvez, o revés do revés. Se for o caso, trata-se de uma ironia filosófica. Hegel desdenha Beethoven, talvez por receio da supremacia que a música absoluta passava a representar, talvez por desconfiança do caminho para o qual a poética beethoveniana parecia apontar, e receio de que ele pudesse se tornar hegemônico. De todo modo, identificado nas entrelinhas, o compositor prova a fragilidade da estética hegeliana com uma obra-refutação. Mas se Beethoven provou a eficácia da associação da poesia de Schiller com a música, só provou-a usando-a num contexto poiético que pode conotar um apelo à simplicidade musical, o que, à revelia e colateralmente comprova a (outra) tese de Hegel. Ao fim e ao cabo a profundidade da poesia de Schiller (e de qualquer outra) é, nas mãos habilidosas de um grande compositor, absolutamente compatível com música. Porém, Beethoven sabe: é preciso aquele equilíbrio entre complexidades do qual Hegel falava.

Eis um fechamento à altura de um estudo que pode ser lido também como uma fantasia filosófica: talvez um justo empate. No entanto, é óbvio que a hermenêutica de uma relação como essas, mesmo não sendo uma especulação livre, é quase inexaurivel, e se relação for invertida, caberia ainda examinar em que sentido a poesia de Schiller poderia ser considerada no âmbito desta complexidade apontada. Mas então se estaria adentrando no universo do logos próprio de outra forma de arte. Permanece, de qualquer modo, que um estudo como este deixa contribuições que transcendem o objeto especifico da análise, pois coloca em foco a própria possibilidade de abordagem da arte em suas possibilidades técnicas diversas na sua relação com a filosofia, consequência também da possibilidade de exame da relação entre artistas e filósofos. 


\section{Referências}

DAHLHAUS, Carl. Estética Musical. Tradução de Artur Morão. São Paulo: Edições 70, 2003.

HECEL, G. W. F. Cursos de Estética. Volume III. Tradução de Marco Aurélio Werle e Oliver Tolle. Consultoria: Victor Knoll. São Paulo. Edusp, 2002 [1835].

HECEL, G. W. F. Estetica. II manoscritto della «Bibliothèque Victor Cousin». A cura di Dario Giugliano. Turim. Giulio Einaudi Editore, 2017.

KANT, Immanuel. Critica da Faculdade do Juizo. $3^{\circ}$ ed. Trad. Valerio Rohden e António Marques. Rio de Janeiro: Forense Universitária, 2012 [a partir da 2 edição alemã, 1793].

PAREYSON, Luigi. Estética - Teoria da Formatividade. Trad. Ephraim Ferreira Alves. Petrópolis: Vozes, 1993 [ $1^{10}$ ed. 1954].

PAREYSON, Luigi. Os Problemas da Estética. Trad. Maria Helena Nery Garcez. $3^{\circ}$ ed. São Paulo: Martins Fontes, $2001\left[^{10}\right.$ ed. italiana 1966].

SCHINDLER, Anton. The Life of Beethoven. Ed. Ignaz Moscheles. Trad. Henrich Döring. Boston: Oliver Ditson Company, 1900 [184 I].

SENNER, Wayne M.; WALLACE, Robin; MEREDITH, William. The Critical Reception of Beethoven's Compositions by His German Contemporaries, volume 2. University of Nebraska Press - Sample Books and Chapters, 2001.

WAGNER, Richard. Beethoven. Trad. Theodemiro Tostes. Porto Alegre: LEPM Editores S/A, 1987 [ 1870].

WALLACE, Robin. The Critical Reception of Beethoven's Compositions by His German Contemporaries, opus 125. Trad. Ed. Robin Wallace. Center for Beethoven Research, Boston University, 2017.

\section{6}




\section{Sobre o autor}

\section{Lucas Eduardo da Silva Galon (*1980)}

Compositor, multi-instrumentista, regente e pesquisador de Ribeirão Preto. É Doutor e Mestre em Artes - filosofia da música - e graduado em Música, sempre pela ECA-USP. É docente na Universidade de Ribeirão Preto (UNAERP), tendo lecionado também na UfSCar. É diretor artísticopedagógico da Academia Livre de Música e Artes (ALMA), Instituição Aparecido Savegnago e USP Música-Criança. Atua como instrumentista no Brasil Matuto Ensemble. É diretor do Festival Música Nova "Gilberto Mendes" desde 2017, função que também exerce no Festival Fiato al Brasile na ltália des de 2016 . Atuou como regente na Orquestra Sinfônica de Ribeirão Preto, USP Filarmônica, Orquestra Jovem Acadêmica (ALMA) e dirigiu por 3 anos o Coro Experimental da UNAERP. Tem atuado com frequência como diretor musical e artístico de óperas e concertos internacionais no Brasil, Itália e EUA. Suas obras musicais e trabalhos acadêmicos têm sido com frequência apresentados no Brasil, Portugal, Itália, Suíça e Estados Unidos.

Recebido em 19/11/2019

Aprovado em 17/02/2020 